\title{
The $\mathbf{1 0 0}$ most cited articles on thoracic surgery management of lung cancer
}

\author{
Ke Jin ${ }^{1 \#}$, Quanteng Hu${ }^{1 \#}$, Jianfeng $\mathrm{Xu}^{2 \#}$, Chunlei $\mathrm{Wu}^{1}$, Michael K. Hsin ${ }^{3,4}$, Carmelina C. Zirafa ${ }^{5}$, \\ Nuria M. Novoa ${ }^{6}$, Stefano Bongiolatti ${ }^{7}$, Robert J. Cerfolio ${ }^{8}$, Jianfei Shen ${ }^{1}$, Dehua Ma $^{1}$ \\ ${ }^{1}$ Department of Cardiothoracic Surgery, Taizhou Hospital of Zhejiang Province, Wenzhou Medical University, Linhai 317000, China; ${ }^{2}$ Department \\ of Cardiothoracic Surgery, Shaoxing People's Hospital, Shaoxing Hospital of Zhejiang University, Shaoxing 312000, China; ${ }^{3}$ Department of \\ Cardiothoracic Surgery, Queen Mary Hospital, Hong Kong, China; ${ }^{4}$ Department of Medicine, Hong Kong University, Hong Kong, China; \\ ${ }^{5}$ Minimally Invasive and Robotic Thoracic Surgery, Robotic Multispecialty Center of Surgery, University Hospital of Pisa, Pisa, Italy; ${ }^{6}$ General \\ Thoracic Surgery Service, University Hospital of Salamanca and Institute of Biomedical Research of Salamanca (IBSAL), Salamanca, Spain; \\ ${ }^{7}$ Thoracic Surgery Unit, University Hospital Careggi, Largo Brambilla, 1, 50134, Florence, Italy; ${ }^{8}$ Department of Cardiothoracic Surgery, New York \\ University Langone Health, New York, NY, USA \\ \#These authors contributed equally to this work. \\ Correspondence to: Jianfei Shen; Dehua Ma. Department of Cardiothoracic Surgery, Taizhou Hospital of Zhejiang Province, Wenzhou Medical \\ University, Linhai 317000, China. Email: jianfei051@163.com; madh@enzemed.com.
}

Submitted Oct 24, 2019. Accepted for publication Nov 06, 2019.

doi: $10.21037 /$ jtd.2019.11.14

View this article at: http://dx.doi.org/10.21037/jtd.2019.11.14

\section{Introduction}

Lung cancer is the leading cause of cancer-related deaths worldwide. In 2019, 228,150 new lung cancer cases and 142,670 cancer deaths are projected to occur in the United States (1), and non-small cell lung cancer (NSCLC) accounts for nearly $85 \%$ of all diagnosed cases $(1,2)$. As the US Preventative Services Task Force has released recommendations of computed tomography lung cancer screening for long-term smokers, the incidence of newly diagnosed lung cancer will have a marked increase (3).

Over the past two decades, the therapies for lung cancer have evolved into a mature subspecialty, also being the culmination of a progressive research initiative and the continued innovation of interventional techniques. For operable NSCLC, the current guideline states that VATS lobectomy is the standard operation $(4,5)$. In recent years, a great progress in the clinical treatment and basic research of adjuvant therapy for lung cancer has been obtained, such as chemotherapy, radiotherapy, target therapy, and immunotherapy (6-8).

A large amount of literature is available to thoracic medicine specialists who perform thoracic surgery management of lung cancer. It is difficult to recognize articles of significance since the quality of the literature varies substantially and includes low impact studies and open access journals. An understanding of the available literature and the most heavily cited works will allow for a better understanding of the evidence base when discussing and providing these treatments.

A bibliometric analysis is a quantitative method used to examine the knowledge structure and development of a research field and its publications. Among all the bibliometric methods, the citation analysis is the most common which focuses on citation number and number of citations per year $(9,10)$. It evaluates the impact an article has had on a specific field of medicine by measuring the number of citations an article has received.

Since 1971, the global output of academic research into the management of lung cancer has increased. There has been no specific quantitative analysis on the articles which have had the most significant impact on the treatment of lung cancer been performed. The aim of this study was to perform a citation analysis on the most cited articles in the thoracic surgery management for lung cancer and analyze each article individually, collecting the article type, year of publication, topic of interest, citation index, authorship, country of origin, institution, and level of evidence. 


\section{Methods}

\section{Identification of the top 100 cited articles}

Between July and August 2018, we performed a retrospective bibliometric analysis, identifying articles through the Web of Science (Thomson Reuters, New York, USA) which searches the Science Citation Index Expanded database, allowing access to over 12,000 peer reviewed journals and collected citation data published since 1945 .

Using selected key terms ("lung cancer", "surgery", "lobectomy", "segmentectomy", "pneumonectomy", "wedge resection", "video-assisted thoracic surgery", "thoracotomy"), our search performed between July and August 2018 yielded a total of 18,268 articles. The top 100 articles were identified subsequently which were ranked by the number of citations.

\section{Analysis of the top 100 cited articles}

A further analysis of individual articles was carried out by three reviewers (J Shen, K Jin, and Q Hu) to extract relevant information for the analysis. Individual articles were reviewed to identify the authorship, journal title, journal IF, subject matter, article type (e.g., prospective analysis, retrospective analysis, meta-analysis or systematic review, randomized controlled trial, review article, guideline, technical note, or case report), institution and country of origin, level of evidence, and year of publication. The analysis method used the Australian National Health and Medical Research Council evidence hierarchy (11). Of note, this classification defines clinical guidelines as level I evidence and randomized control trials as level II evidence.

Furthermore, the citation count and citations per year were extracted using the Web of Science. When there was disagreement or discordance between reviewers, the senior author (D Ma) was included to achieve consensus.

\section{Results}

The top 100 articles regarding the thoracic surgery management of lung cancer according to the most citations received are listed in Table 1 .

"Cisplatin-based adjuvant chemotherapy in patients with completely resected non-small-cell lung cancer", published in The New England Fournal of Medicine in 2004, has received totally 1,720 citations, the most citations in the past 14 years. Of note, it also remains the most cited article per year, being cited 122.86 times on average, per year. The article with the lowest number of citations in the top 100 list, "A practical molecular assay to predict survival in resected non-squamous, non-small-cell lung cancer: Development and international validation studies", received 177 citations. Overall, the mean number of citations was 356 , with the top 100 articles cited an average of 26 times per year.

Only one of the top 100 articles was published prior to 1980 (Table 2), with 63\% ( $\mathrm{n}=63)$ published since the year 2000 and $13 \%$ published within the past decade. Eighteen authors contributed four or more articles (Table 3). Rusch, Ginsberg, Johnson, and Livingston have contributed the most articles. Rusch and Ginsberg were the first named authors on four articles each. Rusch is the most published author, appearing on a total of ten articles.

A total of 31 journals made contributions to the top 100 articles with 13 journals providing two or more articles. Of note, four journals provided ten or more articles (Table 4). The journals included fournal of Clinical Oncology (26.303), Fournal of Thoracic and Cardiovascular Surgery (4.88), Annals of Thoracic Surgery (3.779) and Chest (IF 7.562).

A total of 14 countries produced the entirety of the top 100 most cited articles (Figure 1), with the majority originating in the USA (43\%). Japan, the next highest contributor, contributed nine articles. One institution contributed the most to the top 100 (Table 5). The Memorial Sloan-Kettering Cancer Center contributed 18 articles while the University of California contributed nine. Overall, 30 institutions contributed three or more articles each.

Topics covered in each article are grouped and outlined in Table 6. Subject matter included prognosis $(n=21)$, surgical type $(n=20)$, adjuvant therapy $(n=17)$, perioperative outcome $(\mathrm{n}=10)$, and neo-adjuvant therapy studies $(\mathrm{n}=10)$.

Table 7 and Figure 2 summarize the type of clinical study and level of evidence within the top 100 articles. Most of the evidence is level III or IV, with 18 original prospective and 40 original retrospective clinical studies. Overall, there were 42 prospective studies which included 24 level II randomized controlled trials. Five commentaries and eight reviews were included in the top 100 cited articles.

\section{Discussion}

In recent decades, the thoracic surgery management for lung cancer has expanded dramatically. This bibliometric analysis emphasized the top 100 articles relating to the 
Table 1 The 100 'citation classics' regarding the field of lung cancer surgery and the number of calculated annual citations

\begin{tabular}{|c|c|c|c|c|}
\hline Rank & Article & Citations & $\begin{array}{l}\text { Citations } \\
\text { per year }\end{array}$ & PMID \\
\hline 1 & $\begin{array}{l}\text { Cisplatin-Based Adjuvant Chemotherapy in Patients with Completely Resected Non-Small-Cell } \\
\text { Lung Cancer }\end{array}$ & 1,720 & 122.86 & 14736927 \\
\hline 2 & Randomized trial of lobectomy versus limited resection for T1 N0 non-small cell lung cancer & 1,623 & 70.57 & 7677489 \\
\hline 3 & Vinorelbine plus cisplatin vs. observation in resected non-small-cell lung cancer & 1,372 & 105.54 & 15972865 \\
\hline 5 & $\begin{array}{l}\text { Adjuvant vinorelbine plus cisplatin versus observation in patients with completely resected } \\
\text { stage IB-IIIA non-small-cell lung cancer (Adjuvant Navelbine International Trialist Association } \\
\text { [ANITA]): a randomised controlled trial }\end{array}$ & 1,014 & 84.50 & 16945766 \\
\hline 6 & $\begin{array}{l}\text { A randomized trial comparing perioperative chemotherapy and surgery with surgery alone in } \\
\text { resectable stage iiia non-small-cell lung cancer }\end{array}$ & 962 & 40.08 & 8156698 \\
\hline 9 & $\begin{array}{l}\text { Radiotherapy plus chemotherapy with or without surgical resection for stage III non-small-cell } \\
\text { lung cancer: a phase III randomised controlled trial }\end{array}$ & 739 & 82.11 & 19632716 \\
\hline 10 & $\begin{array}{l}\text { Prognosis and survival in resected lung carcinoma based on the new international staging } \\
\text { system }\end{array}$ & 633 & 21.10 & 2842549 \\
\hline 11 & Lymph node mapping and curability at various levels of metastasis in resected lung cancer & 598 & 14.95 & 713589 \\
\hline 12 & $\begin{array}{l}\text { Preoperative chemotherapy followed by surgery compared with primary surgery in resectable } \\
\text { stage I (except T1N0), II, and Illa non-small-cell lung cancer }\end{array}$ & 523 & 32.69 & 11773176 \\
\hline 13 & $\begin{array}{l}\text { Stereotactic ablative radiotherapy versus lobectomy for operable stage I non-small-cell lung } \\
\text { cancer: A pooled analysis of two randomised trials }\end{array}$ & 521 & 173.67 & 25981812 \\
\hline 19 & $\begin{array}{l}\text { A randomized trial of postoperative adjuvant therapy in patients with completely resected } \\
\text { stage II or IIIA non-small-cell lung cancer }\end{array}$ & 419 & 23.28 & 11355584 \\
\hline 20 & $\begin{array}{l}\text { Morbidity and mortality of major pulmonary resections in patients with early-stage lung cancer: } \\
\text { Initial results of the randomized, prospective ACOSOG Z0030 trial }\end{array}$ & 418 & 34.83 & 16488712 \\
\hline 21 & $\begin{array}{l}\text { Systematic review and meta-analysis of randomized and nonrandomized trials on safety and } \\
\text { efficacy of video-assisted thoracic surgery lobectomy for early-stage non-small-cell lung } \\
\text { cancer }\end{array}$ & 406 & 45.11 & 19289625 \\
\hline 22 & Radical sublobar resection for small-sized non-small cell lung cancer: A multicenter study & 402 & 33.50 & 17000286 \\
\hline 23 & Guidelines on the selection of patients with lung cancer for surgery & 394 & 23.18 & 11209097 \\
\hline 24 & $\begin{array}{l}\text { Long-term follow-up of patients enrolled in a randomized trial comparing perioperative } \\
\text { chemotherapy and surgery with surgery alone in resectable stage IIIA non-small-cell lung } \\
\text { cancer }\end{array}$ & 392 & 19.60 & 9792048 \\
\hline 25 & $\begin{array}{l}\text { Survival of patients with resected N2 non-small-cell lung cancer: Evidence for a } \\
\text { subclassification and implications }\end{array}$ & 384 & 21.33 & 10944131 \\
\hline
\end{tabular}

Table 1 (continued) 
Table 1 (continued)

\begin{tabular}{|c|c|c|c|c|}
\hline Rank & Article & Citations & $\begin{array}{l}\text { Citations } \\
\text { per year }\end{array}$ & PMID \\
\hline 26 & $\begin{array}{l}\text { ERS/ESTS clinical guidelines on fitness for radical therapy in lung cancer patients (surgery and } \\
\text { chemo-radiotherapy) }\end{array}$ & 382 & 42.44 & 19567600 \\
\hline 27 & $\begin{array}{l}\text { Effects of Postoperative Mediastinal Radiation on Completely Resected Stage II and Stage III } \\
\text { Epidermoid Cancer of the Lung }\end{array}$ & 375 & 11.72 & 2877397 \\
\hline 28 & The role of surgery in N2 lung cancer & 357 & 11.52 & 3629423 \\
\hline 30 & $\begin{array}{l}\text { Physiologic evaluation of the patient with lung cancer being considered for resectional surgery: } \\
\text { ACCP evidenced-based clinical practice guidelines ( } 2 \text { nd edition) }\end{array}$ & 338 & 30.73 & 17873167 \\
\hline 31 & $\begin{array}{l}\text { Stereotactic body radiotherapy (SBRT) for operable Stage i non-small-cell lung cancer: Can } \\
\text { SBRT be comparable to surgery? }\end{array}$ & 328 & 46.86 & 20638194 \\
\hline 34 & $\begin{array}{l}\text { Preoperative chemotherapy followed by concurrent chemoradiation therapy based on } \\
\text { hyperfractionated accelerated radiotherapy and definitive surgery in locally advanced non- } \\
\text { small-cell lung cancer: Mature results of a phase II trial }\end{array}$ & 307 & 15.35 & 9469351 \\
\hline 35 & $\begin{array}{l}\text { Neutrophil/lymphocyte ratio and its association with survival after complete resection in non- } \\
\text { small cell lung cancer }\end{array}$ & 302 & 33.56 & 19185164 \\
\hline 36 & Wedge resection versus lobectomy for stage I (T1 NO M0) non-small-cell lung cancer & 299 & 14.24 & 9104978 \\
\hline 37 & $\begin{array}{l}\text { The influence of hospital and surgeon volume on in-hospital mortality for colectomy, } \\
\text { gastrectomy, and lung lobectomy in patients with cancer }\end{array}$ & 296 & 18.50 & 11812957 \\
\hline 38 & $\begin{array}{l}\text { Preoperative F-18 fluorodeoxyglucose-positron emission tomography maximal standardized } \\
\text { uptake value predicts survival after lung cancer resection }\end{array}$ & 292 & 20.86 & 15310769 \\
\hline 43 & Adjuvant chemotherapy after complete resection in non-small-cell lung cancer & 275 & 12.50 & 23931022 \\
\hline 44 & $\begin{array}{l}\text { Video-assisted thoracoscopic lobectomy achieves a satisfactory long-term prognosis in } \\
\text { patients with clinical stage IA lung cancer }\end{array}$ & 266 & 14.78 & 10594199 \\
\hline 45 & $\begin{array}{l}\text { Prognostic and predictive gene signature for adjuvant chemotherapy in resected non-small- } \\
\text { cell lung cancer }\end{array}$ & 264 & 33.00 & 20823422 \\
\hline 46 & $\begin{array}{l}\text { Potential impact on survival of improved tumor downstaging and resection rate by preoperative } \\
\text { twice-daily radiation and concurrent chemotherapy in stage IIIA non-small-cell lung cancer }\end{array}$ & 263 & 12.52 & 20823422 \\
\hline 47 & Risk Factors for Acute Lung Injury after Thoracic Surgery for Lung Cancer & 261 & 17.40 & 14633519 \\
\hline 48 & $\begin{array}{l}\text { Evaluation of epidermal growth factor-related growth factors and receptors and of } \\
\text { neoangiogenesis in completely resected stage I-IIIA non- small-cell lung cancer: Amphiregulin } \\
\text { and microvessel count are independent prognostic indicators of survival }\end{array}$ & 256 & 12.80 & 9516978 \\
\hline 49 & $\begin{array}{l}\text { Induction chemoradiation and surgical resection for superior sulcus non-small-cell lung } \\
\text { carcinomas: Long-term results of Southwest Oncology Group trial } 9416 \text { (Intergroup trial 0160) }\end{array}$ & 254 & 23.09 & 17235046 \\
\hline 50 & Sites of recurrence in resected stage I non-small-cell lung cancer: A guide for future studies & 251 & 7.38 & 6512581 \\
\hline
\end{tabular}

Table 1 (continued) 
Table 1 (continued)

\begin{tabular}{|c|c|c|c|c|}
\hline Rank & Article & Citations & $\begin{array}{l}\text { Citations } \\
\text { per year }\end{array}$ & PMID \\
\hline 51 & Lobectomy by video-assisted thoracic surgery (VATS) versus thoracotomy for lung cancer & 246 & 27.33 & 19577048 \\
\hline 53 & $\begin{array}{l}\text { The role of extrapleural pneumonectomy in malignant pleural mesothelioma. A lung cancer } \\
\text { study group trial }\end{array}$ & 243 & 9.00 & 2072706 \\
\hline 55 & $\begin{array}{l}\text { Morbidity and mortality after neoadjuvant therapy for lung cancer: The risks of right } \\
\text { pneumonectomy }\end{array}$ & 238 & 14.00 & 11603428 \\
\hline 56 & $\begin{array}{l}\text { ERCC1 expression is a predictor of survival in resected patients with non-small cell lung } \\
\text { cancer }\end{array}$ & 238 & 18.31 & 15764785 \\
\hline 57 & $\begin{array}{l}\text { Effect of tumor size on prognosis in patients with non-small cell lung cancer: The role of } \\
\text { segmentectomy as a type of lesser resection }\end{array}$ & 236 & 18.15 & 15632829 \\
\hline 59 & miR-34a as a prognostic marker of relapse in surgically resected non-small-cell lung cancer & 234 & 26.00 & 19736307 \\
\hline 60 & Segmental resection spares pulmonary function in patients with stage I lung cancer & 233 & 16.64 & 15223434 \\
\hline 61 & $\begin{array}{l}18 F-F D G \text { uptake as a biologic prognostic factor for recurrence in patients with surgically } \\
\text { resected non-small cell lung cancer }\end{array}$ & 232 & 14.50 & 11801701 \\
\hline 62 & $\begin{array}{l}\text { The Importance of Surgery to Non-Small Cell Carcinoma of Lung with Mediastinal Lymph Node } \\
\text { Metastasis }\end{array}$ & 231 & 7.70 & 2848463 \\
\hline 63 & $\begin{array}{l}\text { The physiologic evaluation of patients with lung cancer being considered for resectional } \\
\text { surgery }\end{array}$ & 229 & 15.27 & 12527570 \\
\hline 64 & Induction chemotherapy before surgery for early-stage lung cancer: A novel approach & 229 & 12.72 & 10694600 \\
\hline 65 & $\begin{array}{l}\text { Outcomes of Sublobar Resection Versus Lobectomy for Stage I Non-Small Cell Lung Cancer: } \\
\text { A 13-Year Analysis }\end{array}$ & 226 & 18.83 & 16863738 \\
\hline 69 & $\begin{array}{l}\text { A Phase III randomized trial of lobectomy versus limited resection for small-sized peripheral } \\
\text { non-small cell lung cancer (JCOG0802/WJOG4607L) }\end{array}$ & 222 & 24.67 & 19933688 \\
\hline 70 & $\begin{array}{l}\text { Similar long-term survival of elderly patients with non-small cell lung cancer treated with } \\
\text { lobectomy or wedge resection within the surveillance, epidemiology, and end results database }\end{array}$ & 222 & 17.08 & 16002941 \\
\hline 71 & $\begin{array}{l}\text { Physiologic evaluation of the patient with lung cancer being considered for resectional surgery: } \\
\text { Diagnosis and management of lung cancer, 3rd ed: American college of chest physicians } \\
\text { evidence-based clinical practice guidelines }\end{array}$ & 221 & 44.20 & 23649437 \\
\hline 72 & $\begin{array}{l}\text { Lymph node involvement, recurrence, and prognosis in resected small, peripheral, non-small- } \\
\text { cell lung carcinomas: Are these carcinomas candidates for video-assisted lobectomy? }\end{array}$ & 220 & 10.00 & 8642812 \\
\hline 73 & $\begin{array}{l}\text { Induction chemoradiation and surgical resection for non-small cell lung carcinomas of the } \\
\text { superior sulcus: Initial results of southwest oncology group trial } 9416 \text { (Intergroup Trial 0160) }\end{array}$ & 217 & 12.76 & 11241082 \\
\hline 74 & $\begin{array}{l}\text { A controlled study of postoperative radiotherapy for patients with completely resected non- } \\
\text { small cell lung carcinoma }\end{array}$ & 214 & 11.26 & 10994397 \\
\hline 75 & $\begin{array}{l}\text { Is segmentectomy with lymph node assessment an alternative to lobectomy for non-small cell } \\
\text { lung cancer of } 2 \mathrm{~cm} \text { or smaller? }\end{array}$ & 212 & 12.47 & 11269480 \\
\hline
\end{tabular}

Table 1 (continued) 
Table 1 (continued)

\begin{tabular}{|c|c|c|c|c|}
\hline Rank & Article & Citations & $\begin{array}{l}\text { Citations } \\
\text { per year }\end{array}$ & PMID \\
\hline 76 & $\begin{array}{l}\text { A prospective randomized trial to determine the benefit of surgical resection of residual disease } \\
\text { following response of small cell lung cancer to combination chemotherapy }\end{array}$ & 212 & 8.83 & 7988254 \\
\hline 77 & $\begin{array}{l}\text { Neoadjuvant chemotherapy and radiotherapy followed by surgery in stage IIIA non-small-cell } \\
\text { carcinoma of the lung: Report of a cancer and leukemia group B phase II study }\end{array}$ & 212 & 8.15 & 1321893 \\
\hline 78 & $\begin{array}{l}\text { Prognostic factors in patients with resected stage I non-small cell lung cancer. A report from } \\
\text { the Lung Cancer Study Group }\end{array}$ & 211 & 6.21 & 6478416 \\
\hline 79 & $\begin{array}{l}\text { What happens to patients undergoing lung cancer surgery? Outcomes and quality of life before } \\
\text { and after surgery }\end{array}$ & 211 & 13.19 & 12114334 \\
\hline 80 & $\begin{array}{l}\text { Thoracoscopic Lobectomy Facilitates the Delivery of Chemotherapy after Resection for Lung } \\
\text { Cancer }\end{array}$ & 206 & 18.73 & 17383320 \\
\hline 81 & $\begin{array}{l}\text { Prognostic significance of CCND1 (cyclin D1) overexpression in primary resected non-small- } \\
\text { cell lung cancer }\end{array}$ & 205 & 9.32 & 8562333 \\
\hline 84 & $\begin{array}{l}\text { Prognostic assessment of } 2,361 \text { patients who underwent pulmonary resection for non-small } \\
\text { cell lung cancer, stage I, II, and IIIA }\end{array}$ & 201 & 11.17 & 10669677 \\
\hline 85 & $\begin{array}{l}\text { Evaluation of microRNA expression profiles that may predict recurrence of localized stage I } \\
\text { non-small cell lung cancer after surgical resection }\end{array}$ & 200 & 25.00 & 20028859 \\
\hline 86 & $\begin{array}{l}\text { Epidermal growth factor receptor overexpression correlates with a poor prognosis in } \\
\text { completely resected non-small-cell lung cancer }\end{array}$ & 199 & 14.21 & 14679115 \\
\hline 87 & $\begin{array}{l}\text { Preoperative risk evaluation for lung cancer resection: Predicted postoperative product as a } \\
\text { predictor of surgical mortality }\end{array}$ & 198 & 8.25 & 7921468 \\
\hline 88 & $\begin{array}{l}\text { Adjuvant MAGE-A3 immunotherapy in resected non-small-cell lung cancer: Phase II } \\
\text { randomized study results }\end{array}$ & 197 & 39.40 & 23715567 \\
\hline 91 & $\begin{array}{l}\text { Video-Assisted Thoracoscopic Surgery is More Favorable Than Thoracotomy for Resection of } \\
\text { Clinical Stage I Non-Small Cell Lung Cancer }\end{array}$ & 195 & 17.73 & 17532379 \\
\hline 92 & Resection rates and postoperative mortality in 7,899 patients with lung cancer & 194 & 8.82 & 8834326 \\
\hline 93 & Complications of surgery in the treatment of carcinoma of the lung & 191 & 5.31 & 7083931 \\
\hline 94 & Radiotherapy as an alternative to surgery in elderly patients with resectable lung cancer & 185 & 6.17 & 2849147 \\
\hline 95 & $\begin{array}{l}\text { Postoperative radiation therapy in lung cancer: A controlled trial after resection of curative } \\
\text { design }\end{array}$ & 183 & 4.82 & 6998936 \\
\hline 96 & BRCA1: A novel prognostic factor in resected non-small-cell lung cancer & 182 & 16.55 & 17987116 \\
\hline 97 & $\begin{array}{l}\text { Surgical resection of stage IIIA and stage IIIB non-small-cell lung cancer after concurrent } \\
\text { induction chemoradiotherapy: A Southwest Oncology Group trial }\end{array}$ & 182 & 7.28 & 8380477 \\
\hline 98 & Global histone modifications predict prognosis of resected non-small-cell lung cancer & 181 & 16.45 & 17906200 \\
\hline 99 & Cancer recurrence after resection: T1 N0 non-small cell lung cancer & 181 & 6.46 & 2154958 \\
\hline 100 & $\begin{array}{l}\text { A practical molecular assay to predict survival in resected non-squamous, non-small-cell lung } \\
\text { cancer: Development and international validation studies }\end{array}$ & 177 & 29.50 & 22285053 \\
\hline
\end{tabular}


management of NSCLC in the areas of prognosis, surgical type, adjuvant and neoadjuvant therapy, perioperative outcome, recurrence, and second primary tumors. It highlights the high impact literature available for reference in practicing lung cancer therapy. Furthermore, our list of the top 100 articles includes selections which have been

Table 2 The number of articles in the top 100 most cited articles by decade of publication

\begin{tabular}{lc}
\hline Decade & No. of article \\
\hline $1960-1969$ & 0 \\
$1970-1979$ & 1 \\
$1980-1989$ & 11 \\
$1990-1999$ & 25 \\
$2000-2009$ & 50 \\
$2010-2018$ & 13 \\
\hline
\end{tabular}

published across the spectrum of thoracic surgery, including anesthesia, nuclear medicine, radiology, and respiratory medicine, highlighting the multidisciplinary approach to lung cancer.

A prospective multi-institutional trial by Ginsberg et al. compared lobectomy with sublobectomy, and showed that locoregional recurrence was lower in the lobectomy group (12). It has remained highly cited (Web of Science 1623) but also historically relevant (70.23 citations per year). This work provided a guide for the choice of surgery type in clinical practice. Whitson et al. in 2007 demonstrated that VATS lobectomy for patients with clinical stage I NSCLC appeared to be a less morbid operation (Web of Science 195, 17.73 citations per year) (13). Moreover, a meaningful meta-analysis suggests that VATS lobectomy is an appropriate procedure for selected patients with early-stage NSCLC when compared with open surgery (Web of Science 406, 45.11 citations per year) (14).

Table 3 The authors that contributed four or more articles to the 100 most cited articles in lung cancer surgery

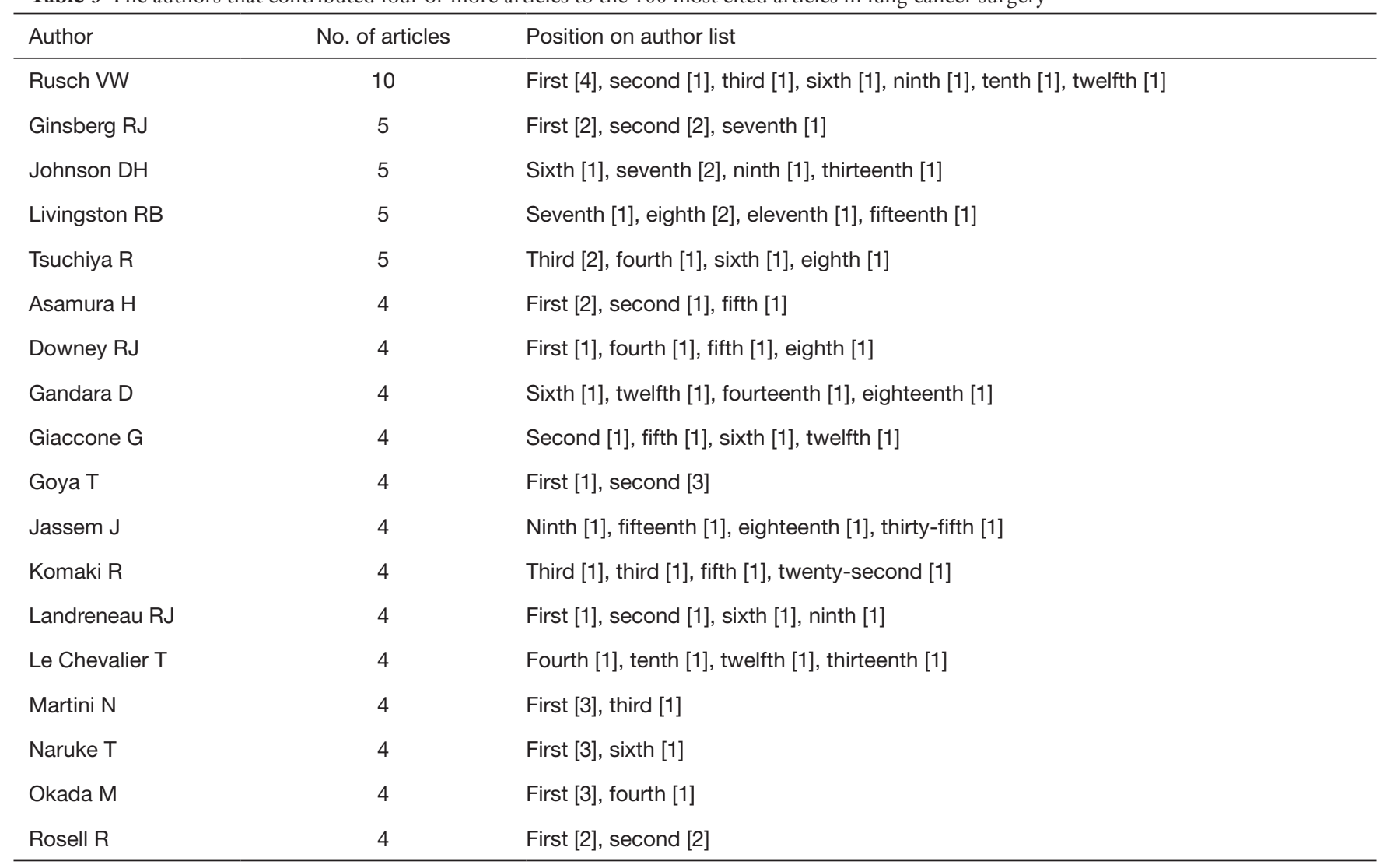


Table 4 The number of articles each journal contributed to the top 100 articles

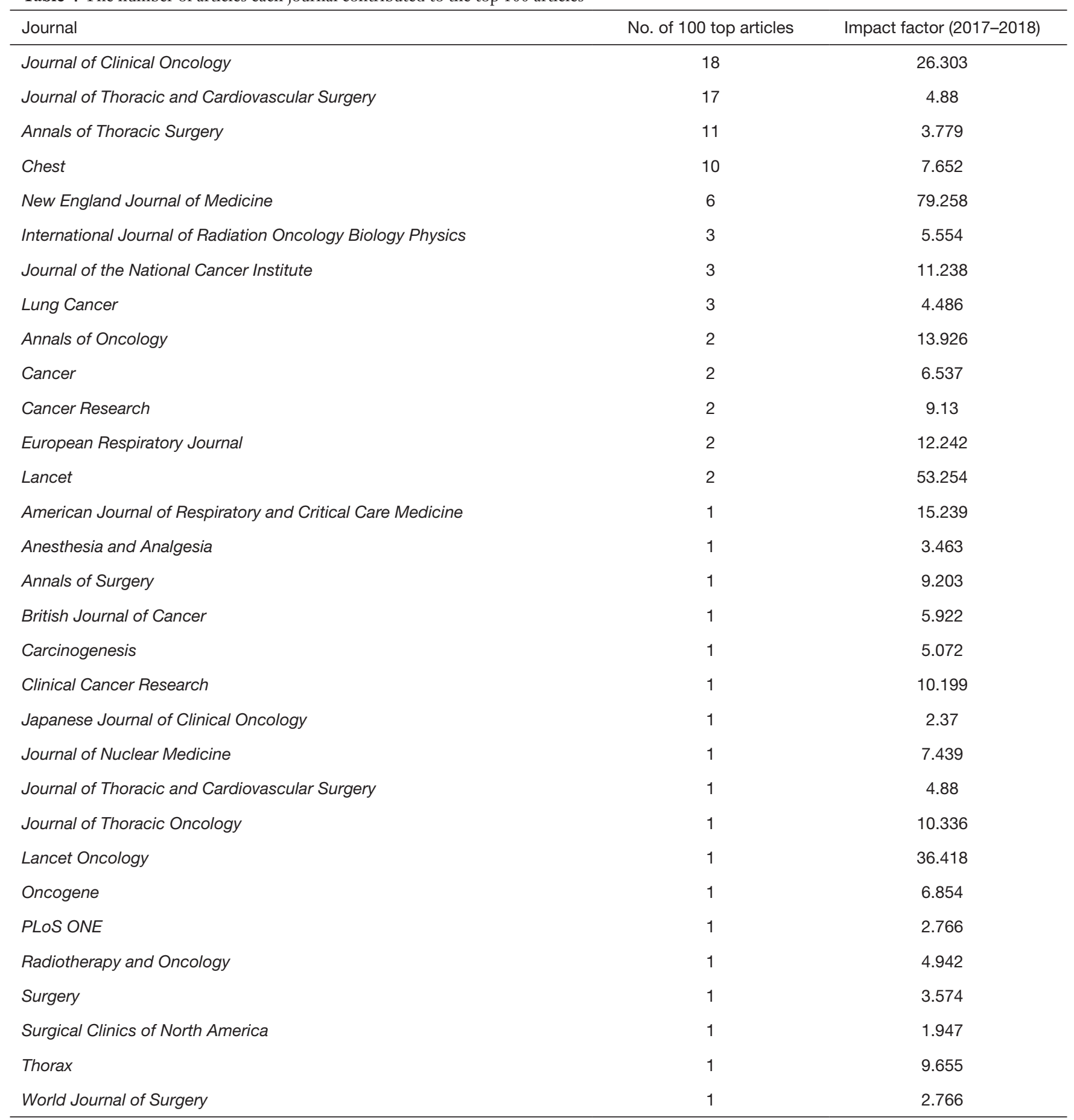

Regarding neoadjuvant and adjuvant chemotherapy, notably in 1994, Rosell et al. described how the preoperative chemotherapy increases the median survival in patients with stage IIIA NSCLC (Web of Science 1095, 45.63 citations per year) (15). In 2004, the International Adjuvant Lung Cancer Trial Collaborative Group concluded that cisplatinbased adjuvant chemotherapy improves survival among patients with completely resected non-small cell lung 

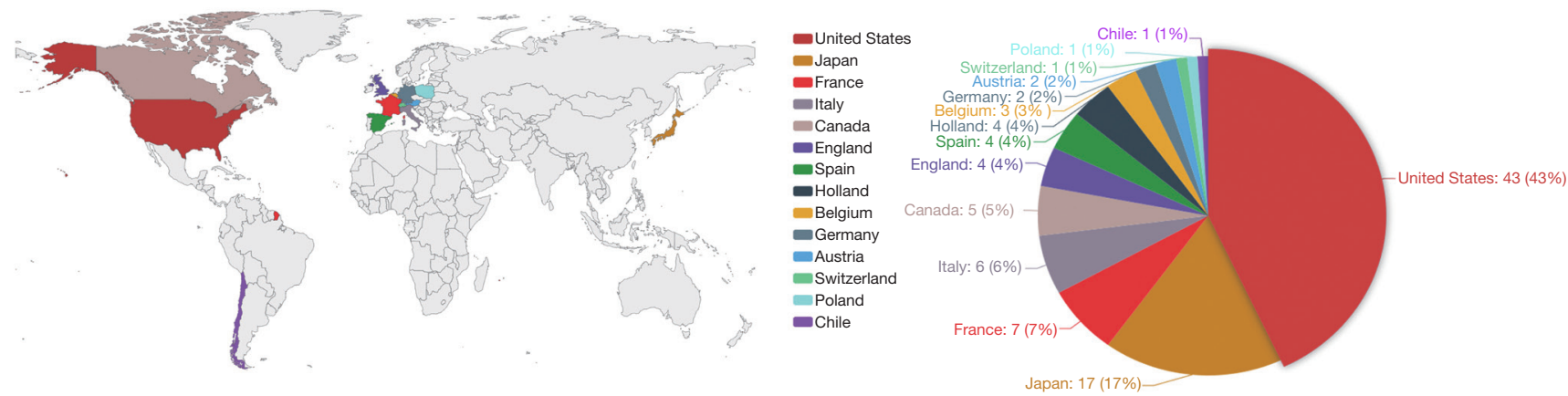

Figure 1 A total of 14 countries produced the entirety of the top 100 most cited articles, with the majority originating in the USA (43\%); Japan, the next highest contributor, contributed nine articles; Australia, Belgium, Switzerland, and Hungary all contributed a single article each.

Table 5 The institutions that contributed the most articles to 100 most cited articles in the lung cancer surgery

\begin{tabular}{lc}
\hline Institution & No. of articles \\
\hline Cornell University Medical Center & 21 \\
University of California & 12 \\
University of Toronto & 17 \\
National Cancer Center Hospital, Japan & 7 \\
University of Texas M.D. Anderson Cancer Center & 7 \\
University of Washington & 6 \\
Mayo Clinic & 6 \\
Fred Hutchinson Cancer Research Center & 5 \\
Brigham and Women's Hospital & 4 \\
Dana-Farber Cancer Institute & 4 \\
Vanderbilt University & 4 \\
Evanston Hospital & 4 \\
Allegheny General Hospital & 3 \\
Fox Chase Cancer Center & 3 \\
Hospital Germans Trias i Pujol & 3 \\
Hyogo Medical Center for Adults & 3 \\
Medical University of South Carolina & 3 \\
Mount Sinai Hospital & 3 \\
National Cancer Institute, Bethesda & 3 \\
Swedish Medical Center & 3 \\
University of Barcelona & 3 \\
University of North Carolina & 3 \\
Veterans Administration Medical Center & 3 \\
Institut Gustave Roussy & 3 \\
\hline & 3 \\
H. Lee Moffitt Cancer Center \& Research Institute & 3 \\
\hline
\end{tabular}

cancer (Web of Science 1720, 122.86 citations per year) (16). In 2006, Douillard et al. compared the effect of adjuvant vinorelbine plus cisplatin versus observation on survival in patients with completely resected NSCLC [Adjuvant Navelbine International Trialist Association (ANITA)], better defining indication of adjuvant chemotherapy (Web of Science 1014, 84.50 citations per year) (17).

A bibliographic analysis aiming to identify and review the 100 most-cited papers in general thoracic surgery was published in 2018 (18). Ding et al. focused on surgical treatment of diseases in the lung, esophagus, trachea, pleura, chest wall and mediastinum and offered insights into the development and advances of general thoracic surgery which could help us understand the evidential basis of clinical decision-making today in this area. However, to our knowledge, there is no other bibliographic analysis of the literature surrounding the thoracic surgery management of lung cancer using Web of Science results. Our analysis had some strengths, including the focused analysis of the thoracic surgery management spanning a range of medical disciplines, including many topics not discussed in prior analyses. The analysis contained a high proportion of original articles, including a higher proportion of randomized controlled trials compared with other similar bibliographic analyses.

However, there are several limitations which should be considered in this bibliometric analysis. While providing a literature overview, the analysis does not provide or allow for any conclusions as to the quality or merit of individual articles. Older articles are more likely to be cited regardless of their impact or relevance accumulating more citations over time. Importantly, many important discoveries do not 
Table 6 The main topics discussed within the 100 most cited articles in lung cancer surgery

\begin{tabular}{ll}
\hline Subject & No. of articles \\
\hline Prognosis & 21 \\
Surgical type & 20 \\
Adjuvant therapy & 17 \\
Perioperative outcome & 10 \\
Neoadjuvant therapy & 10 \\
Radiotherapy vs. surgery & 6 \\
Recurrence and second primary tumors & 5 \\
Guidelines & 5 \\
Other & 6 \\
\hline
\end{tabular}

Table 7 Levels of evidence and article type composing the 100 most cited articles in lung cancer surgery

\begin{tabular}{|c|c|c|}
\hline Level of evidence & Article type & No. of articles \\
\hline I & Guidelines & 5 \\
\hline II & Randomized controlled trial & 24 \\
\hline III & Original prospective & 18 \\
\hline IV & Original retrospective & 40 \\
\hline \multirow[t]{2}{*}{ V } & Commentary & 5 \\
\hline & Review & 8 \\
\hline
\end{tabular}

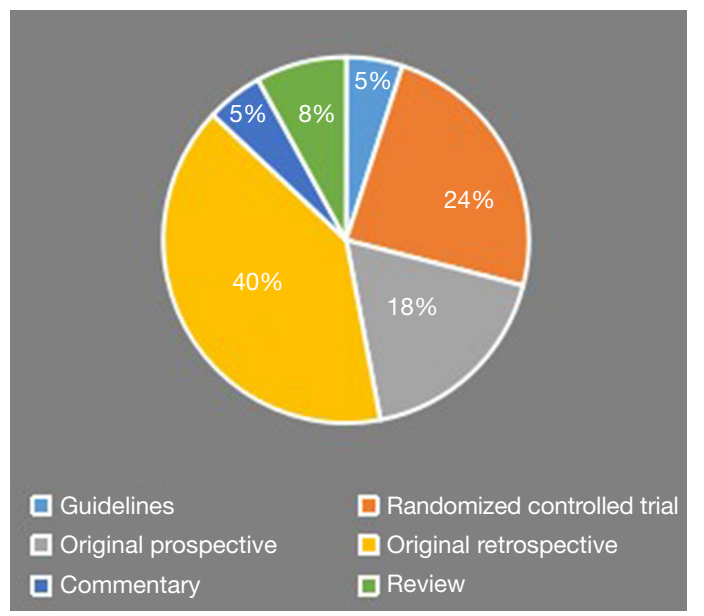

Figure 2 A summary of the levels of evidence composing the 100 most cited articles in the thoracic surgery management of lung cancer. make the top 100 list as their findings are often accepted as general knowledge by the scientific community and subsequently not heavily cited. Furthermore, there is often an influence on citation patterns due to citation bias and social relations within the scientific community (including self-citations), influence by publication structures, and low rates of non-English language citations.

\section{Questions to be further considered:}

\section{What are the future directions of surgical treatment of lung cancer?}

\section{Expert opinion 1: Dr. Michael K. Hsin}

There are many trends which suggest the likely pathway of the future of surgical treatment of lung cancer. I will address a few of such trends which I believe will be particularly significant.

The increasingly common findings of subcentimeter lesions and GGOs, as a result of lung cancer screening, or just incidental findings as CT scans are performed with increasing frequency.

This will lead to the following issues:

(I) While the findings of the two large multicenter RCTS that address the issue of sublobar resection versus lobectomy-the Japanese RCT: JCOG0802/ WJOG4607L, and the North American RCT CALGB 140503-are eagerly anticipated, we are already witnessing an increasingly common use of sublobar resection in the thoracic surgical community for the treatment of small lesions, including GGOs.

(II) Following on the previous point, there will be increasing effort to develop sophisticated and reliable means for the accurate localization of these small lung lesions, such as the routine use of $3 \mathrm{D}$ CT reconstruction in the preoperative planning, electromagnetic navigational bronchoscopy with or without intraoperative real time CT imaging (19).

(III) The incorporation of ablative therapy into the armamentarium of treatment for small lung cancers in appropriately selected patients. These include cryotherapy, microwave ablation and radiofrequency ablation, which may be administered percutaneously, via endobronchial approach, or minimally invasive surgery.

(IV) The advent of immunotherapy has significantly altered the landscape of advanced stage lung cancer treatment. 
There are already a sleuth of clinical trials looking at the role of neoadjuvant immunotherapy in resectable lung cancer. For example, the NEOMUN trial looks at neoadjvant Pembrolizumab as part of a multimodality treatment in resectable Stage II/IIIA NSCLC (20). The role of neoadjuvant PD-1 blockade in resectable early stage lung cancer has been reported in pilot studies (21). However, the role of immunotherapy for early stage resectable lung cancer will be better defined by the results of phase 3 studies with long term outcomes by ongoing studies such as Checkmate 816, IMpower030, and KEYNOTE-671.

\section{Expert opinion 2: Dr. Carmelina C. Zirafa}

Since the introduction of thoracoscopy, at the beginning of the 20th century, the surgical treatment of lung cancer has been characterized by a reduction of invasiveness, in terms of surgical approach and impact on the patient's life. Thanks to the improvement of technology, currently, it is possible to perform also complex procedures by minimally invasive surgery, represented by video-assisted thoracic surgery (VATS) and robotic surgery. In VATS the introduction of even more peculiar and technologically advanced devices, like 3D high definition view and energy devices, enables to do major surgical procedure routinely (22). Moreover, robotic surgery, that is considered the evolution of VATS in terms of technology, permits to approach also complex surgical operations in a safe and comfortable way. In fact, chest wall or vascular invasion, neoadjuvant therapy or prior thoracic surgery are no longer considered contraindications to robotic surgery, as described by various Authors (23).

Furthermore, integration of advanced technological devices will be able to support challenging operations, like electromagnetic-navigational bronchoscopy or fluorescent imaging system (24). In addition, the recent introduction in the practical field of the $3 \mathrm{D}$ printing, a promising radiologic model, could become a consistent support for surgeons to plan the surgical procedure tailored to the patient's case, to reduce time of surgery and be that extra aid that might significantly reduce intraoperative complications (25). In future, $3 \mathrm{D}$ printing could represent a stimulating basis for educational program and as well as the new frontier for biomaterial implant (26).

The development of minimally invasive technique is one of the main elements of the new approach to surgery, in which the fulcrum is the quality of life of patients. Consequently, diffusion of programs such as ERAS and the reduction of invasiveness during the anesthesiologic phase, in particular intubation and analgesia management, is fundamental $(27,28)$.

Considering this background, the future of surgery in lung cancer appears to be exponentially less traumatic and technologically advanced.

\section{Expert opinion 3: Dr. Nuria M. Novoa}

Probably, I would highlight three main lines in the future development around surgical treatment of lung cancer.

The first is related to the controversy: lobectomy versus sublobar resection. Currently, we have sound retrospective data supporting lobectomy over any other sublobar resection whenever the patient can tolerate the resection and even for $1 \mathrm{~cm}$ tumors scenario (29). However, prospective data are mandatory to determine the role of each technique and the best strategy in different groups of patients. Two randomized control ongoing studies had been designed to assess this problem the CALGB 140503 and the Japanese study (JCOG0802/ WJOG4607L) (30). The first study is currently reporting initial results on morbimortality (31) and discussing the need of a preoperative diagnosis for a correct enrollment and assignment (32) but no data on overall survival and local relapse, the most relevant issues, had been published yet. The second is still on going and no initial results had been reported. I look forward with great interest to the results of these studies.

The second pertinent line is related to the impact of the developing immunotherapy on surgical treatments. Again, very promising results had been reported (21) but further information is needed. And, finally, lung cancer screening. Although the results of the NLST (33) were very relevant and induced the introduction of the screening in the USA at a national scale, the raised a lot of unsolved questions that other posterior trials are trying to clarify (34).

\section{Expert opinion 4: Dr. Stefano Bongiolatti}

Nowadays the treatment options for early stage or metastatic stage NSCLC are well-established while some controversial issue are present regarding the multimodal approach on locally advanced stage (IIIA). From an historical point of view, the thoracic surgeon evolved from thoracotomic lobectomy to minimally invasive anatomical pulmonary resection (VATS, RATS, uniportal, subxyphoidal etc.) while the oncological treatment has evolved to a more targeted therapy. In my opinion, these targeted strategies (EGFR-TKI, ALK-inhibitors, ROS1TKI, immunotherapy) associated with local treatment will be the new direction in the multimodal approach of 
locally advanced NSCLC. However, some randomized controlled trial and multi-institutional studies are necessary to demonstrate the safety, feasibility and benefits of this intention treatment approach.

\section{Expert opinion 5: Dr. Robert J. Cerfolio}

Almost all of lung cancer surgery will be done minimally invasively over the next few years. In our own practice, we have already essentially achieved a $100 \%$ robotic approach for all lung cancer, including patients that had chemo and radiation, patients who require a sleeve of the artery or the bronchus and even patients who have tumors greater than $10 \mathrm{~cm}$. We make it a daily work now with zero conversions in our last 200-300 robotic procedures. In the next 5-7 future years, all T1A and T1b tumors will all be treated with bronchoscopic intervention either using heat or thermal or other ablative forms of treatment via the bronchoscope and/or using the injection of immunotherapy.

\section{Should guidelines be established for early-stage lung cancer, especially for GGO?}

\section{Expert opinion 1: Dr. Michael K. Hsin}

There are two aspects to this question:

(I) The management of a GGO where there is no histological diagnosis.

(II) The surgical treatment, if deemed appropriate, of GGO that has been proven to be malignant.

There are already several well-established guidelines on the management of GGO without histological diagnosis, such as the Fleischner society and NCCN guidelines, and no doubt as we gain more experience, new guidelines will be written to reflect the accumulated knowledge.

The management of GGOs known to have malignant potential is fraught with difficulty. What is missing is not so much guideline but good evidence. The main issue centers around whether to perform a lobectomy or a sublobar resection; and for sublobar resection, then which typesegmentectomy or wedge resection?

The decision leading to the appropriate management of GGOs should include the following considerations:

- Consolidation-to-tumour ratio.

- Impact of spread through air space.

- Intraoperative lymph node sampling.

- The place of intraoperative frozen section for resection margins and lymph nodes.

- Solitary GGO vs. multiple GGOs vs. GGO with concurrent proven lung cancer in a different lobe (same side/different side).

\section{Expert opinion 2: Dr. Carmelina C. Zirafa}

The increasingly frequent detection of small pulmonary lesions, due to latest enhancement of screening programs or to incidental detection, has encouraged the diagnosis and treatment of earlier stages of lung cancer. The recurring undefined characteristics of these small lesions, among which the GGO have taken on more relevance in the recent years, have made it necessary to define some guidelines. Several national and international guidelines have been published in the last years, albeit sometimes, disagreeing on the management of small or stable GGOs (35).

The optimisation and homogeneity of indications of different guidelines are essential to limit surgical resection in benign lesions or to avoid delay in diagnosis in case of malignancy. In addition, there are still some confounding elements in the evaluation of indeterminate small lesions, like the presence of multiple lesions, the indication to nonsurgical biopsy and which is better surgical strategy to be applied in order to avoid overtreatment (36).

Specifically, guidelines are lacking in surgical indications. Minimally invasive surgery should be recommended for resection, although depending on the dimensions of these lesions the support of intraoperative localization techniques (e.g., radio-guided resection, near-infrared fluorescence localization, hook wire placement) is required. Currently, some important points of discussion, not yet fixed, in GGO are the kind of pulmonary resection to be preferred (wedge resection $v s$. anatomical resection) and the role of lymphadenectomy (37). According to the proposal of JCOG (Japan Clinical Oncology Group) a wedge resection should be favoured for lesions smaller than $2 \mathrm{~cm}$, whereas larger lesions require anatomical resection (segmentectomy, lobectomy). Whilst waiting for the results of randomized trials and updated guidelines, the treatment of undefined lesion should be always evaluated by a multidisciplinary oncology board.

\section{Expert opinion 3: Dr. Nuria M. Novoa}

There is no doubt that GGO are a special subgroup of lung cancer patients that need specific considerations. For that reason, a guideline is needed to pool all the current information allowing to design a clear management strategy for these patients. The European Society of Thoracic Surgery (ESTS) is currently collaborating in the development of this guideline. 
Expert opinion 4: Dr. Stefano Bongiolatti

The guidelines for every stage NSCLC are a continuous and strenuous process to define the clinical and pathological stage in order to find a right treatment choice. In the last years, with the diffusion of CT-screening programs, new radiological findings (for example ground glass opacities, part-solid nodules, solid nodules associated with cystic airspaces) were frequently identified and are associated with specific subtypes of NSCLC, in particular adenocarcinoma. Furthermore, these adenocarcinoma subtypes are correlated with particular survival patterns. In my opinion, the current international guidelines must consider these features, but it is necessary to clear some aspects of multiple or multifocal ground glass opacity that could be locally treated as primary cancer, instead of a metastatic disease.

\section{Expert opinion 5: Dr. Robert J. Cerfolio}

Yes, there is a plethora of patient with GGO, especially of non-smoking women, and most of them have several in their lungs. Although we only focus on the invasive or solid component of these tumors, but certainly overtime we are going to get more and more information about how to optimize therapy.

\section{The role of surgical treatment in stage IV lung cancer.}

\section{Expert opinion 1: Dr. Michael K. Hsin}

Survival for patients with stage IV NSCLC is poor. Fiveyear survival is $1 \%$ (38). Surgery can be offered for patients with stage IV lung cancer for either palliation or in highly selected patients with the goal of improving prognosis.

The indications for palliation are well established, and include drainage and pleurodesis for malignant pleural effusion, pericardial window for pericardial effusion, airway intervention such as disobliteration/dilatation and stenting for central airway obstruction.

In terms of surgery for improving prognosis in stage IV lung cancer, it remains controversial. There is limited amount of published evidence most of which are from small single center series and focus on patients with oligometastasis. The number of patients with oligometasis remains low and is estimated to be $2-7 \%$ $(39,40)$. In general, the fewer the metastasis, the better the prognosis. In patients with solitary metastasis, 5-year survival close to $50 \%$ has been achieved after surgery, whereas when there are five metastases, this dropped to $17 \%$ after surgery (41).
The presence or absence of nodal disease can affect survival significantly. Tamura reported that for Stage IV N0 NSCLC patients, median survival was 18 months after surgery. However, when there is nodal metastasis as well, the median survival after surgery was 11 months (42).

Most of the publications on surgery in Stage IV NSCLC patients pertain to brain or adrenal metastasis, and it should be emphasised that these represent highly selected patient populations. The best results of aggressive treatment in oligometastasis to the brain is probably by Daniels, who reported that after lung resection and resection of the brain metastasis, 5 -year survival of $60 \%$ was achieved (43). Lanuti reviewed published series where there was synchronous oligometastasis NSCLC to the brain, and concluded that 5-year survival averages 21\% (range 1-35) (44).

For NSCLC with oligometastasis to the adrenal, in carefully selected patients, Raz et al. reported a 5-year overall survival of $34 \mathrm{a} \%$ for patients who underwent resection of adrenal metastasis, and $0 \%$ for those managed non-surgically. Worse survival was seen in patients with contralateral adrenal metastasis or mediastinal lymph node involvement (45). In a systematic review by Tanvetyanon et al. where they performed a pooled analysis of 114 patients from 10 published series, they showed that median overall survival was shorter for patients with synchronous metastasis than those with metachronous metastasis (12 months $v s$. 31 months). However, the 5-year survival estimates were equivalent at $26 \%$ and $25 \%$, respectively (46). The ACCP evidence-based guideline on oligometastatic adrenal metastases recommend that in patients with a synchronous resectable N0, N1 primary NSCLC and an isolated adrenal metastasis with no other sites of metastases, resection of the primary tumor and the adrenal metastasis is recommended. In patients who have undergone a curative resection of an isolated adrenal metastasis, adjuvant chemotherapy is suggested (47).

The role of surgery in extracranial, extra-adrenal NSCLC oligometastasis is less clear. Salah performed a systematic review on patients who underwent resection of the metastasis and definitive treatment of the lung primary $(\mathrm{n}=62)$. The 5 -year survival rate was $50 \%$ for the entire cohort. Mediastinal lymph node involvement was independently predictive of inferior outcome. Similarly, patients with intra-thoracic stage III disease had an inferior outcome compared to patients with stage II and stage I disease. Other factors including site of metastasis have no effect on outcome (48). 


\section{NSCLC in contralateral lung}

According to the $8^{\text {th }}$ edition of the IASLC classification, NSCLC in the contralateral lung is grouped under M1a. It is not always possible to differentiate between a metastatic disease, or multifocal localized disease, which have significantly different prognostic implications. Bertolaccini advocate that in a fit patient with a full preoperative staging including also a negative video-mediastinoscopy, aggressive therapy should be encouraged. On the other hand, if there is regional nodal involvement ( $\mathrm{pN} 1 / \mathrm{N} 2)$, then the benefit of aggressive surgery should be carefully reconsidered (49). All oligometastatic patients should always be discussed in a multidisciplinary meeting. Surgical options include lobectomy for the dominant lesion and sublobar resection for the lesser lesion. Alternatively, in some patients, sublobar resection may be done on one side and stereotactic ablation may be offered for the contralateral side.

A recent multicenter phase II randomized controlled trial from MD Anderson/London Ontario/Colorado compared local consolidative treatment, i.e., definitive radiotherapy or surgery to all sites of known disease, to maintenance treatment/observation. They showed that in patients with oligometastasis (3 or fewer metastases), following frontline systemic therapy and who showed no disease progression at 3 months or more, the local consolidative therapy group is superior for both progression free survival (median 14.2 vs. 4.4 months, $\mathrm{P}=0.022$ ), and overall survival (median 41.2 vs. 17.0 months, $\mathrm{P}=0.017$ ), with no differences in grade 3 or greater toxicities between the two groups. This exciting work is practicing changing and will for sure generate significant impetus for more aggressive treatment of appropriately selected patients with oligometastases (50).

\section{Expert opinion 2: Dr. Carmelina C. Zirafa}

Despite the progress in the treatment of lung cancer, unfortunately the prognosis of clinical IV stage NSCLC is still negative. Hence the surgical treatment should be considered only for selected cases of advanced stage of lung cancer, considering also the promising outcomes obtained with new chemotherapy strategies. In selected IV stage cases, the survival in patients treated with resection of the primary lesion has been proven to be better than in non-surgical subjects, rising a 5 -year-survival of about $20-40 \%$ (51). According to NCCN (National Comprehensive Cancer Network) guidelines, the satisfying prognosis following the radical surgery in selected cases encourages the surgical option. In the analysis of prognostic factors after surgery in patients with advanced disease, the nodal involvement appears to be an independent predictor of a worse prognosis, being $\mathrm{N} 2$ positivity associated with a reduction in survival when compared to N0 and N1 (52). In IV stage, other negative prognostic factors after surgery are: higher $\mathrm{T}$ status, presence of malignant pleural effusion, more of 2 metastases and surgical resection different from lobectomy (wedge resection, segmentectomy, pneumonectomy) (53).

Accurate staging remains fundamental to select limitedsite oligometastatic N0-1 patients with good performance status for surgical treatment, to reach the best therapeutic option and to improve oncologic outcomes.

\section{Expert opinion 3: Dr. Nuria M. Novoa}

Current data supports the utility of surgery in stage IV whenever a proper selection of the patients is done (54). Probably a better knowledge of the biological stress test is needed in order to better define the population that will really benefit from undergoing surgery. This is an interesting study line. As I mentioned before, the introduction of the immunotherapy and the use of target therapies probably will increase the number of patients with oligo-recurrences or oligo-progression and this is a population that clearly benefit from the resection strategy. Still a lot of new achievements should come, and we need to be ready to adapt to the new circumstances. I am clearly optimist about the future of stage IV patients.

\section{Expert opinion 4: Dr. Stefano Bongiolatti}

Published data regarding the surgical/local treatment of metastatic lung cancer are controversies because, in my opinion, there is a lack in the definition of the "oligometastatic state" as affirmed by Hellman and Weichselbaum in 1995. Several progresses have been made in the diagnostic, staging and treatment fields, but the scientific community needs a universally accepted definition of oligometastatic state. Patients with oligometastatic NSCLC demonstrated favourable overall survival when treated with an intention to cure multidisciplinary plan, but some clinical conditions are mandatory although not universally stated. Several questions can arise from this situation. First of all, the number of metastases which can be locally treated. Second, the site and the treatment modality (surgery or radiation therapy) are not welldefined. Third, the treatment should be the same for patient with synchronous or metachronous metastases? Despite all these questions, the most important criterion that every clinician should follow in the decision-making 
process for NSCLC in stage IV, is an accurate and invasive staging and consequently absence of lymph nodal hilar or mediastinal metastasis (N0 disease). Some robust data are necessary to well define this controversial topic and perhaps the definition of metastatic or oligometastatic disease may change thanks to the future developments and clinical applications of new biomarkers such as circulating tumour cells (CTCs) and circulating cell-free DNA or RNA.

\section{Expert opinion 5: Dr. Robert J. Cerfolio}

Interestingly as surgeons, although we would have a shrinking or decreasing role in the treatment of $\mathrm{T} 1 \mathrm{a}$ and T1b tumors, we would concomitantly play a more important role in the treatment of patients with stage III and stage IV cancers.

We have done for years with patients of adenocarcinoma who have solitary metastatic lesions of the brain or adrenal, plural-based disease with multiple lesions, or even those with hepatic disease or nodules in other parts of the lung.

Nowadays even patients with multiple plural based modules would receive resection of the primary tumor two or three years later when they were diagnosed with stage IV cancer. A rogue metastasis is resistant to the targeted therapy.

\section{How should we think of citation ranking of articles in the field of lung cancer surgery?}

\section{Expert opinion 1: Dr. Carmelina C. Zirafa}

In the last decades, treatment and prognosis of lung cancer have been in continuous evolution and several papers have been published to report these changes. The analysis of the top 100 cited articles on lung cancer has underlined the heterogeneity of the evaluated aspects in literature. The principal elements studied by the Authors was the impact of neoadjuvant and adjuvant chemotherapy and radiotherapy in patients undergoing surgery for lung cancer, the extension of surgical resection, the post-operative oncologic outcomes, the application and the results of minimally invasive surgery and the investigation of prognostic factors for resected NSCLC (e.g., clinical characteristics, gene mutations). Usually, the higher citation ranking corresponds to a relevant impact of the paper on the clinical and scientific field, yet the reverse might not always be true. In fact, some outstanding article not have a high citation count, due to the fact that the number of citations can be influenced not only by the quality of the research but also by other factors, such as the author's relevance in the scientific community or to self-citations.

\section{Expert opinion 2: Stefano Bongiolatti}

In my opinion, it could be difficult to change some universally accepted ranking methods as the use h-index. For example, this score should be improved removing selfcitation or inserting a function that analyse the type of study performed and the author position in the authors' list. In this way, more information and more precise details will be included into the score.

\section{Expert opinion 3: Dr. Nuria M. Novoa}

The only way to know the relevance of any work is looking at its repercussion in the rest of the scientific community. How to measure it? Using a ranking system. The current metrics is based on the number of citations of every published paper. Based on it you can calculate the author's Impact Factor and the h-index among others or you can measure the citations of each individual paper. No index is perfect. For instance, the IF is a good system although refinements are necessary. For example, not all the papers published in one journal received the same number of citations, but all received the same IF based on the IF of the journal. Moreover, it does not distinguish between the type of manuscript. Therefore, manuscript from originals to letters to the editor or review papers have the same IF. One interesting problem is self-citation. Some journals and some disciplines favor self-citation meanwhile others penalized it. In my opinion, unless you are working in a very specific area, self-citation is not a good option. Nowadays knowledge grows thanks to little steps made by different members of the community and all them deserve the benefit of their contribution. I am sure that refinements will take place in the current metric system although I consider it a good one. The relevance of this paper relays in the fact that reviews the greatest contributions in the knowledge of lung cancer, the major topic of our specialty.

\section{Expert opinion 4: Dr. Robert J. Cerfolio}

I'm not quite sure how to give a clear objective answer to this question. My first question is why is it important? Why do we have to rank the articles of lung cancer from the most important to the least important? Why should we strive to do this thing?

It is like ranking which movie, which book or which painting is the best. Is there any inherent subjectivity and why does it matter?

Currently the only metric is the impact factor of the 
journal in which the article published. But the number of times that an article is referenced is heavily biased. I think if we ask ourselves what is the most important article in the field of lung cancer surgery, it should be the one which has the largest influence or one that improves the therapy effect for most patients, which means that it has the greatest value.

\section{Conclusions}

This study provides an important and comprehensive overview of the most cited articles in the field of the thoracic surgery management of lung cancer over the past 40 years. It recognizes the important contributions made by key authors and institutions to the field and provides an important framework to a better understanding of the evidence base behind the multidisciplinary treatment of lung cancer.

\section{Acknowledgments}

None.

\section{Footnote}

Conflicts of Interest: The authors have no conflicts of interest to declare.

Ethical Statement: The authors are accountable for all aspects of the work in ensuring that questions related to the accuracy or integrity of any part of the work are appropriately investigated and resolved.

\section{References}

1. Siegel RL, Miller KD. Cancer statistics, 2019. CA Cancer J Clin 2019;69:7-34.

2. Chen $W$, Zheng R, Baade PD, et al. Cancer statistics in China, 2015. CA Cancer J Clin 2016;66:115-32.

3. Aberle DR, Adams AM, Berg CD, et al. Reduced lungcancer mortality with low-dose computed tomographic screening. N Engl J Med 2011;365:395-409.

4. National Comprehensive Cancer Network. Non-small Cell Lung Cancer (Version 3. 2019-January 18, Available online: https://www.nccn.org/professionals/physician_gls/ pdf/nscl.pdf.

5. Brunelli A, Charloux A, Bolliger CT, et al. ERS/ESTS clinical guidelines on fitness for radical therapy in lung cancer patients (surgery and chemo-radiotherapy). Eur
Respir J 2009;34:17-41.

6. van Meerbeeck JP, Kramer GW, Van Schil PE, et al. Randomized controlled trial of resection versus radiotherapy after induction chemotherapy in stage IIIA-N2 non-small-cell lung cancer. J Natl Cancer Inst 2007;99:442-50.

7. Effects of postoperative mediastinal radiation on completely resected stage II and stage III epidermoid cancer of the lung. N Engl J Med 1986;315:1377-81.

8. Azuma K, Ota K, Kawahara A, et al. Association of PDL1 overexpression with activating EGFR mutations in surgically resected nonsmall-cell lung cancer. Ann Oncol 2014:25:1935-40.

9. Garner RM, Hirsch JA, Albuquerque FC, et al. Bibliometric indices: defining academic productivity and citation rates of researchers, departments and journals. J Neurointerv Surg 2018;10:102-6.

10. Mering M. Bibliometrics: understanding author-, articleand journal-level metrics. Serials Review 2017;43:41-5.

11. Merlin T, Weston A, Tooher R. Extending an evidence hierarchy to include topics other than treatment: revising the Australian 'levels of evidence'. BMC Med Res Methodol 2009;9:34.

12. Ginsberg RJ, Rubinstein LV. Randomized trial of lobectomy versus limited resection for T1 N0 non-small cell lung cancer. Lung Cancer Study Group. Ann Thorac Surg 1995;60:615-22; discussion 613-22.

13. Whitson BA, Andrade RS, Boettcher A, et al. Videoassisted thoracoscopic surgery is more favorable than thoracotomy for resection of clinical stage I non-small cell lung cancer. Ann Thorac Surg 2007;83:1965-70.

14. Yan TD, Black D, Bannon PG, et al. Systematic review and meta-analysis of randomized and nonrandomized trials on safety and efficacy of video-assisted thoracic surgery lobectomy for early-stage non-small-cell lung cancer. J Clin Oncol 2009;27:2553-62.

15. Rosell R, Gomez-Codina J, Camps C, et al. A randomized trial comparing preoperative chemotherapy plus surgery with surgery alone in patients with non-small-cell lung cancer. N Engl J Med 1994;330:153-8.

16. Arriagada R, Bergman B, Dunant A, et al. Cisplatinbased adjuvant chemotherapy in patients with completely resected non-small-cell lung cancer. $\mathrm{N}$ Engl J Med 2004;350:351-60.

17. Douillard JY, Rosell R, De Lena M, et al. Adjuvant vinorelbine plus cisplatin versus observation in patients with completely resected stage IB-IIIA non-small-cell lung cancer (Adjuvant Navelbine International Trialist 
Association [ANITA]): a randomised controlled trial. Lancet Oncol 2006;7:719-27.

18. Ding H, Song X, Chen L, et al. The 100 most-cited papers in general thoracic surgery: a bibliography analysis. Int J Surg 2018;53:230-8.

19. Zhao ZR, Lau RWH, Ng CSH. Electromagnetic avigation bronchoscopy in hybrid theater. Front Surg 2019;6:10.

20. Eichhorn F, Klotz LV, Bischoff H, et al. Neoadjuvant antiprogrammed death-1 immunotherapy by pembrolizumab in resectable nodal positive stage II/IIIa non-small-cell lung cancer (NSCLC): the NEOMUN trial. BMC Cancer 2019; 19:413.

21. Forde PM, Chaft JE, Smith KN, et al. Neoadjuvant PD-1 blockade in resectable lung cancer. N Engl J Med 2018;378:1976-86.

22. Vannucci F, Gonzalez-Rivas D. Is VATS lobectomy standard of care for operable non-small cell lung cancer? Lung Cancer 2016;100:114-9.

23. Chen S, Geraci TC, Cerfolio RJ. Techniques for lung surgery: a review of robotic lobectomy. Expert Rev Respir Med 2018;12:315-22.

24. Abbas A, Kadakia S, Ambur V, et al. Intraoperative electromagnetic navigational bronchoscopic localization of small, deep, or subsolid pulmonary nodules. J Thorac Cardiovasc Surg 2017;153:1581-90.

25. Gillaspie EA, Matsumoto JS, Morris NE, et al. From 3-dimensional printing to 5-dimensional printing: enhancing thoracic surgical planning and resection of complex tumors. Ann Thorac Surg 2016;101:1958-62.

26. Kwok JKS, Lau RWH, Zhao ZR, et al. Multi-dimensional printing in thoracic surgery: current and future applications. J Thorac Dis 2018;10:S756-63.

27. Rogers LJ, Bleetman D, Messenger DE, et al. The impact of enhanced recovery after surgery (ERAS) protocol compliance on morbidity from resection for primary lung cancer. J Thorac Cardiovasc Surg 2018;155:1843-52.

28. Boisen ML, Rao VK, Kolarczyk L, et al. The year in thoracic anesthesia: selected highlights from 2016. J Cardiothorac Vasc Anesth. 2017;31:791-9.

29. Dai C, Shen J, Ren Y, et al. Choice of surgical procedure for patients with non-small-cell lung cancer $\leq 1 \mathrm{~cm}$ or $>1$ to $2 \mathrm{~cm}$ among lobectomy, segmentectomy, and wedge resection: a population-based study. J Clin Oncol 2016;34:3175-82.

30. Nakamura K, Saji H, Nakajima R, et al. A phase III randomized trial of lobectomy versus limited resection for small-sized peripheral non-small cell lung cancer (JCOG0802/WJOG4607L). Jpn J Clin Oncol
2010;40:271-4.

31. Altorki NK, Wang X, Wigle D, et al. Perioperative mortality and morbidity after sublobar versus lobar resection for early-stage non-small-cell lung cancer: post-hoc analysis of an international, randomised, phase 3 trial (CALGB/Alliance 140503). Lancet Respir Med 2018;6:915-24.

32. Mitchell KG, Antonoff MB. Encouraging early outcomes in cancer and leukemia group B (CALGB)/Alliance 140503: patient selection, not extent of resection, is the key to perioperative success. Ann Transl Med 2019;7:S50.

33. National Lung Screening Trial Research Team, Aberle DR, Adams AM, et al. Reduced lung-cancer mortality with low-dose computed tomographic screening. N Engl J Med 2011;365:395-409.

34. van Iersel CA, de Koning HJ, Draisma G, et al. Risk-based selection from the general population in a screening trial: selection criteria, recruitment and power for the DutchBelgian randomised lung cancer multi-slice CT screening trial (NELSON). Int J Cancer 2007;120:868-74.

35. Sihoe ADL, Cardillo G. Solitary pulmonary groundglass opacity: is it time for new surgical guidelines? Eur J Cardiothorac Surg. 2017;52:848-51.

36. Ueda K, Hayashi M, Tanaka N, et al. Surgery for undiagnosed ground glass pulmonary nodules: decision making using serial computed tomography. World J Surg 2015;39:1452-9.

37. Hattori A, Matsunaga T, Takamochi K, et al. Radiological classification of multiple lung cancers and the prognostic impact based on the presence of a ground glass opacity component on thin-section computed tomography. Lung Cancer 2017;113:7-13.

38. Carnio S, Novello S, Mele T, et al. Extending survival of stage IV non-small cell lung cancer. Semin Oncol 2014;41:69-92.

39. Mordant P, Arame A, De Dominicis F, et al. Which metastasis management allows long-term survival of synchronous solitary M1b non-small cell lung cancer? Eur J Cardiothorac Surg 2012;41:617-22.

40. Albain KS, Crowley JJ, LeBlanc M, et al. Survival determinants in extensive-stage non-small-cell lung cancer: the Southwest Oncology Group experience. J Clin Oncol 1991;9:1618-26.

41. Hanagiri T, Takenaka M, Oka S, et al. Results of a surgical resection for patients with stage IV non-small-cell lung cancer. Clin Lung Cancer 2012;13:220-4.

42. Tamura T, Kurishima K, Watanabe H, et al. Characteristics of clinical N0 metastatic non-small cell lung cancer. Lung 
Cancer 2015;89:71-5.

43. Daniels M, Wright GM. Complete resection of non-smallcell lung cancer and oligo-metastatic brain disease. ANZ J Surg 2005;75:963-6.

44. Lanuti M. Surgical Management of Oligometastatic NonSmall Cell Lung Cancer. Thorac Surg Clin 2016;26:287-94.

45. Raz DJ, Lanuti M, Gaissert HC, et al. Outcomes of patients with isolated adrenal metastasis from non-small cell lung carcinoma. Ann Thorac Surg 2011;92:1788-92; discussion 1793.

46. Tanvetyanon T, Robinson LA, Schell MJ, et al. Outcomes of adrenalectomy for isolated synchronous versus metachronous adrenal metastases in non-small-cell lung cancer: a systematic review and pooled analysis. J Clin Oncol 2008;26:1142-7.

47. Kozower BD, Larner JM, Detterbeck FC, et al. Special treatment issues in NSCLC: diagnosis and management of lung cancer, 3rd ed. American College of Chest Physicians evidence-based clinicalpractice guidelines. Chest 2013;143:e369S-99S.

48. Salah S, Tanvetyanon T, Abbasi S. Metastatectomy for extra-cranial extra-adrenal non-small cell lung cancer solitary metastases: systematic review and analysis of

Cite this article as: Jin $\mathrm{K}, \mathrm{Hu} \mathrm{Q}, \mathrm{Xu} \mathrm{J}, \mathrm{Wu} \mathrm{C}, \mathrm{H} \sin \mathrm{MK}$, Zirafa CC, Novoa NM, Bongiolatti S, Cerfolio RJ, Shen J, Ma D. The 100 most cited articles on thoracic surgery management of lung cancer. J Thorac Dis 2019;11(11):48864903. doi: $10.21037 /$ jtd.2019.11.14 reported cases. Lung Cancer 2012;75:9-14.

49. Bertolaccini L, Pardolesi A, Forti Parri SN, et al. Surgical approaches in patients with oligometastatic non-small cell lung cancer. Bonfanti B, Brandolini J, Solli P. J Thorac Dis 2018;10:498-502.

50. Gomez DR, Tang C, Zhang J, et al. Local consolidative therapy vs. maintenance therapy or observation for patients with oligometastatic non-small-cell lung cancer: longterm results of a multi-institutional, phase II, randomized Study. J Clin Oncol 2019;37:1558-65.

51. Yang CJ, Gu L, Shah SA, et al. Long-term outcomes of surgical resection for stage IV non-small-cell lung cancer: a national analysis. Lung Cancer 2018;115:75-83.

52. Kawano D, Takeo S, Katsura M, et al. Surgical treatment of stage IV non-small cell lung cancer. Interact Cardiovasc Thorac Surg 2012;14:167-70.

53. Chikaishi Y, Hirai A, Imanishi N, et al. We should be done in such a way that patients with stage IV non-small cell lung cancer who would benefit from surgery are not overlooked. J Thorac Dis 2018;10:S3257-9.

54. Novoa NM, Varela G, Jiménez MF. Surgical management of oligometastatic non-small cell lung cancer. J Thorac Dis 2016;8:S895-S900. 